\title{
OFICINA DE FANDANGO COMO EDUCAÇÃO POPULAR NA COMUNIDADE TRADICIONAL CAIÇARA - JUREIA/IGUAPE/SP
}

\author{
Dulcinéia de Fátima Ferreira ${ }^{(*)}$ \\ Paulo Cesar Franco
}

\section{INTRODUÇÃO}

Com a globalização da economia, as experiências sociais locais sofreram brutalmente as conseqüências da força do modelo de racionalidade ocidental capitalista. A partir da vivência e dos estudos que realizamos, pudemos identificar diversas situações nas quais a cultura ${ }^{1}$ tradicional caiçara foi afetada por essa lógica.

Mesmo sabendo que as culturas estão sempre em movimento, é importante destacar que nesta pesquisa focamos nosso olhar sobre o modo como a "naturalização das diferenças e o universalismo/globalização" (SANTOS, 2007) atua sobre as culturas. Conforme Santos (2007) através da naturalização das diferenças a racionalidade ocidental atua de modo a inferiorizar, desqualificar o que não é global e universão como não hegemônico, portanto como inferior, local e residual.

Nesse movimento de produção do sentimento de inferioridade, insignificância, irrelevância e impotência do modelo hegemônico globalizado, identificamos a experiência de Educação Popular das Oficinas de Fandango, realizadas pela Associação dos Jovens da Juréia (AJJ), ${ }^{2}$ como uma

\footnotetext{
${ }^{(*)}$ Dulcinéia de Fátima Ferreira. Professora Adjunto da UFSCar-Sorocaba - Departamento de Ciências Humanas e Educação (DCHE) e Programa de Pós Graduação em Educação (PPGEd) - Líder do Grupo de Pesquisa Educação Comunidade e Movimentos Sociais (GECOMS). E-mail: dulceferreira@ufscar.br.

Paulo Cesar Franco. Licenciado em Filosofia, Pedagogia e Mestre em educação pela Universidade Federal de São Carlos-UFSCar - Campus Sorocaba. E-mail: pcfranco15@gmail.com.

1 “A cultura é concebida como modos, formas e processos de atuação dos homens na história, na qual ela se constrói. Está constantemente se modificando, mas ao mesmo tempo, é continuamente influenciada por valores que se sedimentam em tradições e são transmitidos de uma geração para outra.” (GOHN, 2005, p.98)

Cultura como "[...] um campo no qual uma comunidade institui as relações entre seus membros e com a natureza, conferindo-lhes sentido ao elaborar símbolos e signos, práticas e valores, ao definir para si própria o possível e impossível, a linha do tempo (passado, presente e futuro), as distinções no interior do espaço, o verdadeiro e o falso, o belo e o feio, o justo e o injusto, o permitido e o proibido, a relação com o visível e o invisível, com o sagrado e o profano, a guerra e a paz a vida e morte.” (CHAUÍ, 2006, p. 131)

${ }^{2}$ A Associação dos Jovens da Jureia-AJJ é uma entidade sem fins lucrativos fundada em 1994, na comunidade caiçara da Barra do Ribeira, Iguape/SP, com objetivo de resgatar e dar continuidade a cultura caiçara que entrou em processo de desaparecimento com a Criação da Estação Ecológica da Jureia, unidade de conservação integral da natureza.
}

Revista Teias v. 18, n. 50, 2017 (Jul./Set.): Conversas sobre formação de professores, práticas e currículos 
experiência contra-hegemônica, que resistem à lógica da monocultura, e apresentam-se como fissuras no modelo de "vida para o consumo" (BAUMAN, 2008) instituído, pois anunciam as possibilidades de outros modos de vida.

De acordo com Santos (2000), o modelo de racionalidade ocidental capitalista hegemônico apresenta-se como um modelo arrogante, pois propõe-se como sendo o único modo de existir, desconsiderando e desvalorizando a multiplicidade de formas de vida e saberes em curso.

O modo invisível, como este modelo de racionalidade atua sobre as experiências, produz nas subjetividades o sentimento de não-existência. "Há produção de não-existência sempre que uma dada entidade é desqualificada e tornada invisível, ininteligível, ou descartável de modo irreversível" (SANTOS, 2004, p. 787). Esta produção de subjetividades conformadas é parte de uma política que atua de modo a transformar o que é local em algo insignificante, irrelevante, localizado, por isso, inferior ao que é global ou universal. Procuram transformar as experiências sociais locais em nada, ou quase nada e as pessoas, os agentes sociais em ninguém.

Assim como a dinamicidade cultural, as subjetividades/identidades também estão em permanente movimento,

“[...] algo formado, ao longo do tempo, através de processos inconscientes, e não algo inato, existente na consciência no momento do nascimento. Existe sempre algo "imaginário" ou fantasiado sobre sua unidade. Ela permanece sempre incompleta, está sempre "em processo", sempre "sendo formada (HALL, 1992, p.10)".

Assim o modo como o caiçara se vê, também é afetado de diversas formas. É nesse cenário, marcado por progressiva segregação e exclusão, ${ }^{3}$ que processos de silenciamento e de produção da impotência vão se constituindo, e, conforme Bauman (1999), afetando o modo de vida das pessoas com consequências perversas.

As comunidades Tradicionais Caiçaras da Jureia, localizadas no município de Iguape, litoral sul do Estado de São Paulo, também foram afetadas por esta lógica. A partir da década de 1980, se viram ameaçadas de viver sua cultura em seu território de origem, pois o governo paulista iniciou

\footnotetext{
3 "O conceito de exclusão é relativamente recente na linguagem das ciências humanas e sociais, embora por trás dele se esconda uma realidade nada nova. São por demais conhecidos os fatos da fome, da convivência com a injustiça, do não acesso aos meios de saúde e da educação, de discriminação de raça e de gênero, enfim, tudo aquilo que faz com que alguém seja menos gente. A linguagem nova é sinal de que esta mesma realidade se apresenta com cara diferente e, portanto, como um novo desafio prático e epistemológico". (STRECK, 2001, p. 51).
}

Revista Teias v. 18, n. 50, 2017 (Jul./Set.): Conversas sobre formação de professores, práticas e currículos 
um processo de retirada dos moradores da Jureia por conta das articulações ambientalistas que anunciaram a implantação da Estação Ecológica Jureia-Itatins. ${ }^{4}$

Além das consequências dessa política ambiental, que separa homem-natureza e veio com toda força impondo um processo de desterritorialização, numa perspectiva de que as comunidades tradicionais não faziam parte do meio ambiente, os caiçaras da Jureia sofreram com o avanço da globalização da economia. A desvalorização de formas mais comunitárias de produção, como no caso do mutirão, acompanhada pela lógica da "monocultura do saber" (SANTOS, 2007), passou a produzir na comunidade caiçara um sentimento de inferioridade frente à cultura norte-americana e eurocêntrica, as quais se espalham pelo mundo como sendo o único modo de viver. A comunidade caiçara sofre o processo que Freire (1982) chamou de "invasão cultural”.

Toda invasão sugere, obviamente, um sujeito que invade. Seu espaço histórico-cultural, que lhe dá visão de mundo, é o espaço de onde ele parte para penetrar em outro espaço históricocultural, superpondo aos indivíduos deste seu sistema de valores.

O invasor reduz os homens do espaço invadido a meros objetivos de sua ação. As relações entre invasor e invadidos, que são relações autoritárias, situam seus pólos em relações antagônicas. O primeiro atua, os segundos têm a ilusão de que atuam na atuação do primeiro; este diz a palavra; os segundos, proibidos de dizer a sua, escutam a palavra do primeiro. O invasor pensa, na melhor das hipóteses sobre os segundos, jamais com eles; estes são pensados por aqueles. O invasor prescreve os invadidos são pacientes da prescrição. (FREIRE, 1982, p. 41-2)

É importante ressaltar que "a compreensão do mundo é muito mais ampla do que a compreensão ocidental do mundo" (SANTOS, 2007, p. 20). Por esse motivo, nesta pesquisa, procuramos vasculhar o vivido na intenção de identificar e revelar os modos de compreender e viver desta comunidade caiçara. Também pretendemos apontar o potencial contra-hegemônico das culturas tradicionais e o quanto o modo de vida comunitária, o encontro entre a geração dos antigos com os jovens em torno de uma manifestação cultural nas oficinas de Fandango, podem contribuir para o processo de reterritorialização.

A implantação da Estação Ecológica Jureia-Itatins no final da década, em 1987, restringiu consideravelmente o modo de vida caiçara na Jureia e obrigou as famílias a deixarem suas casas, seu território e sua cultura. Foram forçados a buscar a vida nas periferias das cidades, onde passaram a viver "fazendo bicos" em casas de turistas. Muitos iniciam um processo de

\footnotetext{
${ }^{4}$ A Estação Ecológica da Jureia foi implantada em 1987, em uma área de aproximadamente 80.000 hectares, onde habitavam caiçaras desde o período colonial. Por ser uma unidade de conservação de uso integral, a lei que rege a unidade de conservação proibiu a presença dos caiçaras, causando um conflito que perdura por mais de duas décadas pelo território. Nesse período, mais de 200 famílias foram expulsas de seu território cultural e existencial.
}

Revista Teias v. 18, n. 50, 2017 (Jul./Set.): Conversas sobre formação de professores, práticas e currículos 
desterritorialização, de afastamento do modo de vida caiçara. No entanto, como afirmou Pelbart (2010), tudo racha e estala como no equipamento de um veleiro destroçado. Nunca a dominação é total e, ao lado da dominação, sempre existe a possibilidade da insubordinação.

Ao realizarmos esta pesquisa, percebemos que há "uma mistura nebulosa de potência e fragilidade" (ROLNIK, 2011, p. 85). Em meio à produção do sentimento de inferioridade, de impotência, alguns jovens caiçaras que foram morar com suas famílias na comunidade da Barra do Ribeira, foz do Rio Ribeira de Iguape, no entorno da Estação Ecológica, indignados com a desvalorização da cultura caiçara, criaram, em 1993, a Associação dos Jovens da Jureia - AJJ. Buscavam a criação de um espaço de formação, resgate cultural e geração de renda através do artesanato com a caxeta. ${ }^{5}$

Entediam que somente a manutenção das comunidades tradicionais no seu território de origem poderia possibilitar a sobrevivência da cultura caiçara e de sua peculiaridade, enquanto que o distanciamento do território e das manifestações culturais da comunidade, os saberes tradicionais acabariam ou virariam folclore, como acontece com várias culturas e vem acontecendo com as apresentações de fandango em praças públicas.

A criação da AJJ possibilitou que muitos caiçaras desterritorializados, impedidos de vivenciar a comunidade tradicional, pudessem experienciar um movimento de reterritorialização a partir das rodas de conversas; dos ensaios de fandango; da participação em projetos comunitários, com finalidade de geração de renda através do artesanato da caxeta e processos de formação para compreender a política ambiental; e poder atuar nos encontros e audiências públicas, que diziam respeito às reivindicações dos caiçaras.

A partir de 2006, a AJJ firmou uma parceria com o Ministério da Cultura (MINC) e deu início a um projeto social denominado "Centro de Cultura Caiçara da Barra do Ribeira", que teve como objetivo potencializar o trabalho de artesanato de caxeta como atividades educativas. Foi assim que nasceram as Oficinas de Fandango Caiçara.

Como pesquisadores e integrantes da comunidade caiçara, não nos interessa a repetição do presente, mas a criação de novos territórios existenciais, capazes de contribuir para a afirmação da potência da vida. Afinal, [...],

\footnotetext{
${ }^{5}$ A Caxeta é uma madeira típica da Mata Atlântica de rápida regeneração e excelente para a confecção de artesanato. Por ser de fácil manuseio, os caiçaras herdaram dos indígenas o uso da madeira para confecção e artefatos caseiros e outros usos domésticos. A AJJ usa a caxeta para confeccionar a rabeca e a viola branca, instrumento do fandango caiçara.
} 
[...] a repetição do presente é a repetição da fome e da miséria para uma parte cada vez mais importante da população mundial, é a repetição de novos fascismos transnacionais, públicos e privados, que, sob a capa de uma democracia sem condições democráticas, estão a criar um apartheid global; é, finalmente, a repetição do agravamento dos desequilíbrios ecológicos, da destruição maciça da biodiversidade, da degradação de recursos que até agora garantiram a qualidade de vida na Terra. (SANTOS, 1996, p. 16)

Com essa pesquisa procuramos realizar um trabalho de tradução como sugere Santos (2000, 2007), revelando a potência das experiências locais que se faz presente na vida comunitária, onde a riqueza de saberes dos povos tradicionais caiçaras se expressa na partilha e na alegria da festa do Fandango, encontro caiçara que cultiva o respeito às singularidades dos processos coletivos. Interessa-nos o respeito às diversas formas de produzir, de pensar e viver. $\mathrm{O}$ trabalho que aqui compartilhamos é fruto de um processo de investigação e é, ao mesmo tempo, um projeto de memória, denúncia e anúncio. Pensamos a ciência como possibilidade de emancipação cognitiva e social. Lembrando que:

Todo conhecimento emancipatório é autoconhecimento. Ele não descobre, cria. Os pressupostos metafísicos, os sistemas de crenças, os juízos de valor, não estão antes nem depois da explicação científica da natureza ou da sociedade. São parte integrante dessa mesma explicação. (...) A ciência é, assim, autobiográfica. (...) No paradigma emergente, o carácter autobiográfico do conhecimento-emancipação é plenamente assumido (SANTOS, 2000, p. 834).

Optamos pela concepção de ciência que vê no conhecimento um processo de "emancipação" e não de "regulação" (SANTOS, 1996, p. 25). Nessa forma de pesquisa vemos a investigação como possibilidade de formação e reinvenção do modo de viver. Acreditamos que escrevendo, narrando e refletindo sobre o vivido, assim potencializamos e tornamos credíveis os saberes e o modo de vida caiçara.

\section{O MUTIRÃO DE FANDANGO E O FORTALECIMENTO DOS VÍNCULOS COMUNITÁRIOS}

A Jureia, região localizada na divisa dos municípios de Peruíbe, Iguape, Miracatu, Pedro de Toledo e Itariri, constituiu um espaço geográfico onde os caiçaras se estabeleceram e desenvolveram uma prática de subsistência que coabitavam o mutirão, a agricultura de subsistência, o fandango e os saberes tradicionais adquiridos desde o primórdio da colonização ou tempo dos antigos, como é reconhecido pelos caiçaras.

No tempo dos antigos, o isolamento das comunidades tradicionais na região da Jureia, onde passaram a viver praticando a agricultura de subsistência, contribuiu para que os caiçaras 
desenvolvessem variados vínculos comunitários e saberes que se articulavam com o trabalho de mutirão "uma forma de trabalho coletivo, comum em toda região, onde os vizinhos se reuniam em prol da realização de uma empreitada" (CORRÊA, 2005, p. 28).

A realização do mutirão para plantar uma roça de mandioca, por exemplo, alimento básico da cultura caiçara, acontecia comunitariamente com a presença das famílias vizinhas que se dispunham a ajudar na empreitada da roça.

O mutirão se iniciava com o ritual dos homens amolando suas enxadas, tarefa que necessitava de um local seguro para fixar as ferramentas enquanto as mãos tinham que segurar as extremidades da lima com firmeza para que a colisão entre os metais produzisse a afiação perfeita da ferramenta. Momento de aprendizado que envolvia a todos. Ali a comunidade aprendia olhando o mais experiente desenvolver o ofício que aprendera com seus antepassados.

O cabo da enxada também era testado entre os cavadores da roça, pois a madeira precisava ser de lei para aguentar a puxada do braço. Ninguém se arriscava levar para o mutirão uma enxada que não fosse encabada com as madeiras eleitas pela comunidade. Logo que as enxadas eram amoladas, o chefe de família orientava os participantes pelo caminho da roça, percurso que se fazia enfileirado, onde cada qual levava sua ferramenta na costa em ritmo de cantarolas e conversas descontraídas.

No tempo dos antigos, o mutirão era um modo de produção coletivo que reunia as crianças, jovens e adultos para trabalharem juntos. Enquanto os cavadores levantavam as covas, normalmente as mulheres seguiam afincando as ramas que eram trazidas pelas crianças num cesto de cipó timbopeva $^{6}$ da beira da roça, onde os mais velhos picavam as manivas. $^{7}$

Seguindo o mutirão de plantio, as crianças costumavam brincar nas beiras da roça imitando os afazeres dos adultos, pois no tempo dos antigos o brincar era um modo de experimentar a vida adulta, conforme relata Nicleto Silva, morador da comunidade do Guaraú, em Peruíbe:

O que mais interessava a nós criançada era ver nossos pais com uma foice nas costas e um machado na mão. A gente saia com um pedaço de pau na mão e também ia derrubando as árvores e fazendo as nossas rocinhas. Os mais velhos iam plantar, a gente ficava junto, pequeninho, desse tamanho, a gente se juntava 3, 4 molequinhos, de 7,8 anos: vamos fazer uma roça, vamos... Às vezes, a gente obrigava nossos pais comprar uns podãozinhos [pequenas

\footnotetext{
${ }^{6}$ Timbopeva é um cipó nativo da Mata Atlântica que cresce nos galhos das árvores e, de lá, lança as raízes até o chão. O caiçara sabe o tempo certo para extrair os cipós (raízes) dos quais fabrica os cestos e outros artefatos. O conhecimento da extração e uso da Timbopeva é uma herança da cultura indígena e, portanto, um uso sustentável porque não causa impacto à natureza, uma vez que o vegetal tem regeneração muito rápida.

${ }^{7}$ Manivas são pedaços de ramas que são fincadas nas covas para produzir mandiocas.
} 
foices] pra gente fazer roça. Era a única brincadeira, não tinha outra coisa (Entrevista com Sr. Nicleto Silva, concedida em setembro de 2014).

Vencida a metade do plantio, chegava o horário do café, e todos se reuniam debaixo de uma árvore à beira da roça. Os alimentos eram colocados em comum em volta de um bule de café e uma cuia de farinha manema, ${ }^{8}$ proporcionando o espaço e o momento do reencontro das pessoas. $\mathrm{O}$ compartilhar o alimento na roça apresentava-se como um espaço de trocas de experiências. Momento de partilhar o fruto do trabalho e também os diferentes saberes culturais transmitidos e fortalecedores dos vínculos comunitários.

Do trabalho braçal, seguia-se o ritual da festividade, da comemoração do encontro com a festa do fandango, pois o feitio do mutirão carregava consigo a tradição do encontro, da alegria, da partilha dos alimentos, das rezas, das caminhadas, dos atos voluntários, do namoro, da continuidade da vida que se vivia e celebrava perante um animado baile de fandango que seguia noite adentro.

Nesse modo de produção comunitária, se compartilhava e se reinventava a vida a partir de momentos simples como tomar café na beira da roça, cantarolar nas pescarias, pescar na cachoeira e dançar muito fandango até o sol raiar...

Através do fandango, as comunidades fortaleciam os vínculos de amizade, criavam e recriavam a cultura traduzindo o cotidiano em dança para celebrar a vida. O "Passadinho", por exemplo, é uma dança circular criada na comunidade da Cachoeira do Guilherme, pelo líder espiritual Sátiro Tavares, com o objetivo de evitar brigas entre as famílias.

Outra criação da comunidade foi a dança do "Engenho", a qual imitava os movimentos do equipamento de pilar arroz, que no tempo dos antigos era muito utilizado na região.

Mutirão, reencontro, festa do fandango, vida comunitária são algumas das características da cultura caiçara que esta pesquisa procura potencializar.

\section{OFICINAS DE FANDANGO CAIÇARA NA AJJ COMO EDUCAÇÃO POPULAR: UM MOVIMENTO DE CRIAÇÃO DE NOVOS TERRITÓRIOS EXISTENCIAIS}

Apesar das restrições ambientais que empurraram os caiçaras da Jureia para as periferias urbanas levando consigo boa parte dos saberes da sua cultura, o fandango ainda se mantém vivo,

\footnotetext{
${ }^{8} \mathrm{~A}$ farinha manema, também conhecida por farinha d’água, é granulada e de cor amarelada. Utiliza-se mandioca curtida na água ou "apodrecida". Dai o seu nome: “farinha d'água”. Por ser uma farinha grossa era bastante consumida pelo caiçara que trabalhava na roça no tempo dos antigos.
}

Revista Teias v. 18, n. 50, 2017 (Jul./Set.): Conversas sobre formação de professores, práticas e currículos 
apresentando-se como um elo agregador, revitalizador e produtor de sentidos, atuando como uma mística na resistência cultural e na reinvenção do modo de vida caiçara.

O fandango caiçara,

[...] é uma manifestação cultural popular que reúne dança e música e possui regras estéticas definidas. Em cada localidade, entretanto, existem características específicas, criando assim uma realidade artística rica e variada. [...] a ideia de confraternização e de alegria está intimamente associada ao fandango, realizado sempre sob forma de festa e divertimento coletivo. Não se dança nem se toca fandango sozinho. É preciso no mínimo dois músicos, violeiros de preferência. É preciso também os pares para danças. Isso sem falar de quem faz as comidas, de quem oferece as bebidas, dos construtores dos instrumentos, entre outros. Assim como a maioria das manifestações populares, o fandango envolve uma parcela da comunidade (GRAMANI et al., 2006, p. 21).

A participação do caiçara em uma festa de Fandango é uma possibilidade de reverberação de estados inéditos, capazes de produzir abalos no modo de olhar para si e para sua cultura. A festa comunitária pode mobilizar um mergulho nas lembranças e saudades dos tempos passados, o vasculhar a vida e o recriar sentidos, possibilitando a criação de novos territórios existenciais.

Entre os anos de 2006 a 2012, o Centro de Cultura Caiçara, coordenado pela AJJ, desenvolveu oficinas de fandango caiçara ao modo da educação popular.

Essa iniciativa nasceu com a intenção de valorizar a cultura caiçara e o conhecimento local, os quais vinham se perdendo por conta da forma como as políticas ambientais forçavam a mudança dos mestres artesãos e fandangueiros para as cidades, de modo que acabavam se afastando e abandonando a tradição.

Seguindo na contramão do modelo de racionalidade ocidental, que, segundo Santos (2007) atua na produção do ignorante, do residual, do inferior, do local e do improdutivo, os quais se expressam no sentimento de ausência, de inexistência, o Centro de Cultura Caiçara constitui-se como um território contra hegemônico criando momentos de reflexão, vivências e preservação da cultura tradicional.

A partir das oficinas de fandango como educação popular, investem energia na potência de vida presentes nas experiências que foram produzidas como ausentes. Atuam no sentido de tornar a cultura caiçara presente, existente, potente e capaz de criar novos territórios existenciais. No lugar da lógica da monocultura, imposta pelo modelo de racionalidade ocidental, investe-se nas ecologias de saberes. 
Conforme Santos (p. 32-37) cinco são as ecologias necessárias para invertermos a lógica da monocultura, de modo a tornar presentes experiências produzidas como ausentes, a saber:

a) Ecologia de saberes: atua no sentido de afirmar as diversas formas de conhecer, os diferentes saberes. Valoriza o diálogo entre o saber popular, científico, laico, indígena, camponês, urbano;

b) Ecologia da temporalidade: valorização de outras temporalidades além do tempo linear. Como exemplo, podemos citar: para o camponês, o tempo estacional; para comunidades africanas e indígenas, o tempo da ancestralidade; nessa temporalidade, a história é vista como possibilidade;

c) Ecologia do reconhecimento: propõe um procedimento para descolonizar as nossas mentes de modo que possamos compreender que diferença não é desigualdade;

d) Ecologia da transescala: sugere recuperar o que é local, o que não é apenas efeito da globalização hegemônica, articular projetos, nacionais e globais a partir do local;

e) Ecologia das produtividades: trata de outras formas de sobrevivência, consistindo na recuperação e valorização dos sistemas alternativos de produção, das organizações econômicas populares, das cooperativas operárias, das empresas autogestionadas, da economia solidária etc.

Ao realizarmos esta pesquisa, podemos dizer que a forma dialógica, acolhedora, como as oficinas de fandango aconteciam, abriu brechas para a produção do sentimento de pertencimento à comunidade ao criar espaço para encontros humanos. As oficinas de fandango, consequentemente, possibilitaram que vários atores coletivos "conversassem" sobre as aspirações, os desejos, os desassossegos e os serviços de apoio para construção de sentidos para viver recuperasse seu lugar.

\subsection{Cartografando o saber da experiência}

A experiência, a possibilidade de que algo nos aconteça ou nos toque, requer um gesto de interrupção, um gesto que é quase impossível nos tempos que correm: requer parar para pensar, parar para olhar, parar para escutar, pensar mais devagar, e escutar mais devagar; parar para sentir, sentir mais devagar, demorar-se nos detalhes, suspender a opinião, suspender o juízo, suspender a vontade, suspender o automatismo da ação, cultivar a atenção e a delicadeza, abrir os olhos e os ouvidos, falar sobre o que nos acontece, aprender a lentidão, escutar aos outros, cultivar a arte do encontro, calar muito, ter paciência e dar-se tempo e espaço (BONDIA, 2004. p. 122).

A oficina iniciava-se com a preparação da chegada das pessoas ao Centro de Cultura Caiçara. Como nos tempos dos antigos, o ambiente era preparado para acolher as pessoas. Os 
encontros tinham sempre um tempo para acolhida. ${ }^{9} \mathrm{Na}$ porta de entrada da casa havia sempre alguém a esperar o que chega, trocando-lhes saudações e transmitindo-lhes um sentimento de amizade e companheirismo.

Na companhia de um cafezinho, os jovens da Jureia iam tecendo uma aproximação entre os participantes ${ }^{10}$ e o universo das oficinas. Mostrando o fogão à lenha e os outros artefatos que se espalhavam pelo ambiente da cozinha, os jovens faziam uma breve introdução da iniciativa e a exposição dos objetivos da entidade, até chegar ao assunto propriamente do fandango.

Conduzindo os participantes para a marcenaria, os jovens mostravam os maquinários e as ferramentas necessárias para a produção dos instrumentos, e depois seguiam para o caxetal ${ }^{11}$ onde falavam da história da madeira que se transformaria em instrumentos musicais.

Em meio à Mata Atlântica, com a presença de mestres artesãos e fandangueiros, os jovens realizavam processos de educação ambiental a partir dos saberes dos antigos. Explicavam que a caxeta, madeira típica da Mata Atlântica, abundante no litoral, leve e fácil de trabalhar, cresce em área alagadiça e é muito usada pelos indígenas, que a conhecem como 'pau que não pega formiga'.

No que diz respeito ao impacto ambiental, suspeitado no ato da extração do vegetal, os jovens e os mestres explicavam que a caxeta é uma espécie de madeira sustentável, porque sua regeneração é rápida e essa sabedoria vem desde o tempo dos antigos, um conhecimento caiçara que perpassa séculos demonstrando o respeito que essa comunidade tem pela natureza.

No embalo da oralidade e no aconchego de uma boa prosa, os mestres contavam que os caiçaras são frutos da miscigenação entre indígenas, brancos e negros e por isso herdaram dos antigos o conhecimento da utilização da caxeta para produzir gamelas, colher de pau e, posteriormente, na construção da rabeca e da viola branca, instrumentos utilizados nas festas de fandangos.

Diferentemente da educação bancária, que

[...] faz do processo educativo um acto permanente de depositar conteúdos. Acto no qual o depositante é o 'educador' e o depositário é o 'educando'. (...) na qual o educador é quem disciplina; o educando, o disciplinado; educador é o que fala; o educando, o que escuta; o educador prescreve, o educando, segue a prescrição; o educador escolhe o conteúdo do

\footnotetext{
9 "Significa aceitar sem preconceitos e jovialmente o outro como o outro, em sua diferença. (...) Devemos viver a acolhida jovialmente como quem vê no outro um próximo, um companheiro de caminhada, um irmão e uma irmã, membros da grande família humana, outrora dispersa, e agora reunida na mesma Casa Comum” (BOFF, 2005, p. 167).

${ }^{10}$ Entende-se participante a comunidade caiçara local e adjacente bem como os adeptos pela cultura caiçara da Jureia.

${ }^{11}$ Caxetal é o local onde nasce a caxeta.
} 
programa, o educando o recebe na forma de "depósito"; o educador é sempre quem sabe, o educando, o que não sabe; o educador é o sujeito do processo; o educando seu objeto" (FREIRE, 1974, p. 14).

A realização das oficinas era pensada a partir do "princípio do cuidado" (BOFF, 2001), de modo que os participantes pudessem tecer vínculos mais duradouros entre si e a comunidade. Procurava-se agir em busca de novas formas de encontro com o outro. ${ }^{12}$

Ao vir participar das oficinas de fandango como um de um grupo de educação popular, o que os jovens encontravam era um processo educativo pensado ao modo de uma vivência que acolhe, que considera os interesses e motivações de todos, que valoriza a participação. Encontra um espaço onde sua pessoa tem valor e o que tem a dizer é importante, é reconhecido.

O mestre prepara a madeira a ser utilizada e vai ensinando passo a passo como utilizar cada ferramenta para cuidar da confecção da rabeca, ${ }^{13}$ que geralmente se inicia pelo braço do instrumento.

Na oficina, o convite à vivência de uma experiência inicia-se com o contato do aprendiz com a caxeta mediada pelo mestre. Diante da tora bruta, o aprendiz e o mestre entram num estado de admiração. ${ }^{14} \mathrm{O}$ aprendiz é convidado a deixar de lado seus pensamentos confinados, seus tempos cronometrados e resistir à rapidez do pensamento para entrar no tempo do esculpir. $\mathrm{O}$ mestre convida-os a se perderem no tempo da paciência, do olhar demoradamente cuidadoso e do fazer distraidor...

Essa etapa exige tempo, paciência, atenção, ofício que o artesão vai “entalhando, esculpindo como se imitasse a paciente obra da natureza" (BOSI, 1994, p. 88). Neste ritmo caiçara, a caxeta e o aprendiz vão cedendo à resistência própria de suas estruturas. A serra afiada vai despindo a casca rugosa do vegetal para revelar a superfície macia e propícia como matéria-prima para uma das partes da rabeca. O riscar a superfície macia e leve da caxeta, buscando traçar o projeto do braço da rabeca, lança o aprendiz, inesperadamente num movimento de criação de uma obra de arte.

O processo de confecção do braço da rabeca constitui uma experiência única. O aprendiz fica encantado com a conquista inicial e se lança na busca do resultado final, que é a criação do

\footnotetext{
${ }^{12}$ Buscando com cuidado e delicadeza, "desconstruir barricadas" erguidas durante as durezas da vida. Sabia-se que essa conquista não aconteceria por decreto, mas pela vivência de uma experiência de hospitalidade (XXXXXX, 2006, p. 128).

${ }^{13}$ Segundo Pimentel (2010) é um instrumento de cordas friccionadas encontrada em diversas regiões do país trazida pelo colonizador português e que teria sua origem nos instrumentos árabes como o rebab ou rabab.

14 “Admirar implica pôr-se em face do não-eu, curiosamente, para compreendê-lo” (FREIRE, 1978, p.53).
}

Revista Teias v. 18, n. 50, 2017 (Jul./Set.): Conversas sobre formação de professores, práticas e currículos 
instrumento. Numa das extremidades do braço é feito o caracol, detalhe quase meramente estético do instrumento, não fosse a função de suporte que exerce para as cravelhas que atuam no tencionamento das cordas. O feitio do caracol exige tempo e paciência, e por isso a presença do mestre é fundamental para que o aprendiz consiga "antropofagar a experiência dos detalhes" (ROLNIK, 1989, p. 2).

Nesse ritmo, entre silêncios e processos criativos, o diálogo vai se estabelecendo, e algumas perguntas vão surgindo: algumas sobre a procedência da caxeta, outras sobre o papel da rabeca no ritual do fandango e sua relação com a identidade caiçara. Algumas delas são respondidas no decorrer da oficina, problematizadas, outras ficam à espera, em um processo de sentir e pensar ao modo caiçara.

Admirar-se por sua capacidade de criar uma obra de arte como o braço de uma rabeca, mobiliza no aprendiz estados inéditos que os leva a entrar em contato com o indizível e com aquilo que só se aprende vivendo a potência de sentir-se parte de uma comunidade e de uma tradição e, por isso, o instiga a refletir sobre a própria identidade. O que eu quero com isso? O que eu busco com isso? Indagações que fazem vibrar seu interior e ao mesmo tempo seu papel como caiçara num mundo ocidental capitalista.

Os encontros vão acontecendo no aconchego comunitário, pois "a comunidade é um lugar “cálido", um lugar confortável e aconchegante. É como um teto sob o qual nos abrigamos da chuva, como uma lareira diante da qual esquentamos mão num dia gelado.” (BAUMAN, 2003, p. 7). As pessoas sentem-se parte, e experienciam a composição de vínculos num espaço em que há liberdade para brincar, opinar, para permanecer em silêncio e apurar o olhar... Vivenciam um processo educativo ao modo da educação popular. Aprendem juntos, ao mesmo tempo em que o Mestre ensina fazendo.

O Mestre mostra como aprendeu a fazer. Os jovens se inspiram e mobilizam sua capacidade criadora. Vão dando forma à madeira e vivenciando estados inéditos. Concluída a confecção do braço da rabeca, chega o momento da retirada das tábuas da caxeta para confeccionar a tampa superior e a tampa inferior. Para esculpir essas partes é necessário o uso de um instrumento chamado "alegre", que é feito de uma faca com ponta afiada e entortada em semicírculo, ferramenta fabricada pelo próprio mestre cuja herança é do tempo dos antigos. Enquanto ele coloca o molde da rabeca sobre a superfície aplainada da caxeta, vai contando a história do alegre e compartilhando as experiências dos antigos, as quais são transmitidas de geração em geração, sem perder a atenção e sensibilidade necessárias para se riscar os entornos na madeira que darão o 
formato da rabeca. Na sequência, a tampa bruta é fixada na bancada onde o aprendiz começa a esculpir a madeira com o auxílio do alegre.

$\mathrm{O}$ ato de esculpir um pedaço de caxeta, com atenção aos detalhes e com os cuidados que se deve ter com cada peça, possibilita a experiência da paciência e do calar-se para ouvir os outros e a si mesmo. Os jovens aprendem a ouvir histórias pelas vozes roucas, singelas e sábias dos velhos mestres, de modo que a tradição oral da cultura seja potencializada. É preciso aprender a ouvir as histórias para também aprender a contá-las, como diz Benjamin.

Contar histórias sempre foi a arte de contá-las de novo, e ele se perde quando as histórias não são mais conservadas. Ela se perde quando ninguém mais fia ou tece enquanto ouve a história. Quanto mais o ouvinte se esquece de si mesmo, mais profundamente se grava nele o que é ouvido. Quando o ritmo do trabalho se apodera dele, ele escuta a história de tal maneira que adquire espontaneamente o dom de narrá-las. Assim se teceu a rede em que está guardado o dom narrativo. E assim essa rede se desfaz hoje por todos os lados, depois de ter sido tecida, há milênios, em torno das mais antigas formas de trabalho manual (BENJAMIN, 1994, p. 205).

Entre histórias, o mestre vai orientando como as tampas devem ser cavoucadas pelo aprendiz na superfície central, até que adquiram um formato envergado capaz de produzir o som esperado e característico da rabeca. Nesse movimento, compartilha-se a história da AJJ, o significado do seu projeto comunitário.

Terminadas as tampas, passa-se para o preparo dos aros que serão coladas na lateral das mesmas, com objetivo de uni-las. Para tanto, os mestres novamente entram em cena, ensinando como se retira os aros da madeira com o auxílio da máquina de aplainar. Explica que eles devem ter espessura suficiente para conseguir envergá-los no momento que forem colocados na forma, até que se sujeitem aos contornos desejados. Enquanto os aros das rabecas são preparados, o ambiente calmo do Centro de Cultura possibilita a convivência agradável entre as pessoas. Quando os aros estão prontos, inicia-se o processo de montagem do instrumento, de modo que, num primeiro momento é fixado o braço da rabeca no suporte da forma. Na sequência, ela recebe os aros, e por último a tampa, sendo fixados entre si através de cola específica.

A rabeca chega à fase de acabamento. É nesse momento que o mestre retira o instrumento da forma e o entrega ao aprendiz, que, com ela em mãos, admira-se da obra de arte que criou e põe-se a lixar a parte da madeira externa, para dar o acabamento perfeito. É um momento de encantamento entre o aprendiz e a rabeca. Para isso é necessário conhecer não apenas o tipo de lixa, mas outros saberes que somente o saber de experiência pode auxiliar. Nesse momento, as pessoas escolhem um local aconchegante para se sentar e para realizar esse trabalho. Como um recolher-se, demoradamente, com toda sensibilidade do corpo e da alma, os jovens iniciam um movimento de 
imersão e contemplação da sua obra, ao mesmo tempo em que, pacientemente lixam a parte externa do instrumento em 'estado de parto'.

O mestre ensina a fazer os cavaletes nos quais as cordas serão estendidas, e também as cravelhas, as quais darão os tencionamentos necessários para a produção do som inesperado. Após a fixação das cordas de aço, ainda é confeccionado o arco da rabeca, um objeto de madeira roliço onde são fixadas cordas de nylon - às vezes crina de cavalo - que produzirá o som, em contato com as cordas de aço.

Antes de ensinar a afinação da rabeca, o mestre aconselha a fixar no braço do instrumento, próximo ao caracol, um pedaço de cera, que é usada para passar nas cordas de nylon, a fim de produzirem o ruído sonoro do fandango.

Assim, chega-se ao fim da confecção da rabeca, instrumento do fandango caiçara que, em companhia da viola branca, forma a dupla fandangueira.

Com a rabeca nas mãos, cada participante contempla sua obra de arte, admira e vê de forma materializada o seu potencial criador. Vê-se diante de um instrumento de caxeta, composto não apenas de madeira, mas de uma vivência criativa que, ao ser lapidado produz estados inéditos potencializando a vida a partir de processo libertador.

A vivência proporcionada pela oficina de fandango permitiu que os mestres pudessem compartilhar seus saberes de experiência com a comunidade, revitalizando valores que a lógica capitalista quer consolidar como não existência, ignorância que não deve ser creditada. As oficinas de fandango enquanto educação popular possibilitaram que a comunidade caiçara voltasse no tempo do silencio, do ouvir, do fazer sem pressa e tempo para terminar.

No confeccionar do instrumento surge a oportunidade de mergulhar na história dessa comunidade, que é relatada pelos mestres desde o tempo dos antigos, passando pelo mutirão até chegar ao fandango, onde o caiçara se reinventa através da mística do encontro, da festa, da alegria e da dança que vai até o sol raiar.

Nessa "educação para a liberdade", a partir da participação no "círculo de cultura", 15 os homens e as mulheres se redescobririam como produtores de cultura, compreenderiam a relação do ser humano com a natureza e a possibilidade de transformarem o mundo através do seu

\footnotetext{
15 "Em lugar de professor, com tradições fortemente "doadoras", o Coordenador de Debates. Em lugar de aulas discursivas, o diálogo. Em lugar de aluno, com tradições passivas, o participante de grupo. Em lugar dos "pontos" e de programas alienados, programação compacta, "reduzida" e "codificada" em unidades de aprendizado" (FREIRE, 1980, p. 103).
} 
potencial criador, produzindo cultura. Perceberiam que a educação não é algo distante da vida, mas a possibilidade de recriá-la e, assim, vivê-la melhor.

\section{CONSIDERAÇÕES FINAIS}

Ao desenvolvermos este trabalho de cartografia das oficinas de Fandango como Educação Popular na comunidade Caiçara da Jureia - Iguape, Estado de São Paulo, recolhemos e aqui compartilhamos parte do potencial contra-hegemônico presente nessa experiência local e no modo de vida dessa comunidade tradicional.

Podemos dizer que essa experiência possibilitou a produção do novo, a reinvenção da vida.

Produzir o novo é inventar novos desejos e novas crenças, novas associações e novas formas de cooperação. Todos e qualquer um inventam, na densidade social da cidade, na conversa, nos costumes, no lazer - novos desejos e novas crenças, novas associações e novas formas de cooperação. A invenção não é prerrogativa dos grandes gênios, nem monopólio da indústria ou da ciência, ela é a potência do homem comum. Cada variação, por minúscula que seja, ao propagar-se e ser imitada torna-se quantidade social, e assim pode ensejar outras invenções e novas imitações, novas associações e novas formas de cooperação. (PELBART, 2010, p. 37 $38)$.

Durante toda a pesquisa pudemos acompanhar de perto o potencial criador da cultura tradicional caiçara sempre em movimento e a potência da vida em comunidade .

Todo esse processo que foi descrito fez uso da narrativa no estilo caiçara. Procuramos narrar essa experiência criando um estilo o mais próximo possível do que ela foi vivida. As narrativas produzidas na oficina de fandango perpassaram as experiências educativas vividas na prática, resgatando e valorizando os saberes e a tradição local por meio da mística do fandango enquanto espaço de resistência e re-existência.

A narração é uma forma artesanal de comunicação. Ela não visa a transmitir o "em si" do acontecido, ela o tece até atingir uma forma boa. Investe sobre o objeto e o transforma. Tendência comum dos narradores é começar com a exposição das circunstâncias em que assistiu ao episódio: "Certa vez, ia andando por um caminho quando..." Isso quando conta como não diretamente vivido por ele (BOSI, 1994. p.8 8).

Ao acompanharmos o processo de criação da rabeca, vemos que ele acontece entre o silêncio, a escuta atenta e a oralidade dos mestres. Esse modo de se desenrolar da oficina de Fandango perpassa todas as etapas da confecção da rabeca e se estende para outros universos da cultura caiçara, tal qual o momento em que as pessoas se reúnem para contar e ouvir os "causos" 
sobre a localidade, a fauna, a flora. Como na educação popular que também acontece a partir da oralidade, do diálogo, do vivenciar e compartilhar as experiências.

Então, é... se tratando de oficina de dança é... mais na parte oral mesmo, é mais oralidade mesmo, a gente não tem muita essa prática da escrita, a cultura caiçara não tem muita essa didática da escrita. Então é olhando e fazendo. A gente tem essa facilidade de ensinar, de mostrar pros outros aprenderem, pra gente é fácil fazer isso. Passar na teoria é mais difícil. Então, seria na parte, seria basicamente oral (Entrevista com Cleiton do Prado Carneiro em outubro de 2014).

Durante todo o tempo da oficina, valorizou-se muito o processo criativo do fazer individual e coletivo. As oficinas de fandango mobilizaram encontros, sonhos e a reinvenção da cultura caiçara.

No subterrâneo desta experiência entre narrativa e o processo de criação, cada pessoa inventa seu começo, permitindo-se o movimento de reterritorializar-se como caiçara. Escovamos palavras e compartilhamos a potencialidade dos encontros em tempos de desencontros e desvalorização da vida. 


\section{REFERÊNCIAS}

BAUMAN, Z. Comunidade: a busca por segurança no mundo atual. Rio de Janeiro: Jorge Zahar Ed., 2003.

A vida para consumo: a transformação das pessoas em mercadoria. Rio de Janeiro: Jorge Zahar Ed.,2008.

Globalização: as consequências humanas. Rio de Janeiro: Jorge Zahar, 1999.

BOFF, L. Virtudes para um outro mundo possível: Hospitalidade, direção e dever de todos. Petrópolis, RJ: Vozes, 2005.

Saber Cuidar: Ética do humano - compaixão pela terra. 7. ed. Petrópolis: Vozes, 2001.

BONDÍA, J. L. Notas sobre a experiência e o saber da experiência. In: GERALDI, C.M.G.; RIOLFI, C.R.; GARCIA, M.F. (Orgs.) Escola viva: Elementos para a construção de uma educação de qualidade social. Campinas, SP: Mercado das Letras, 2004.

BOSI, E. Memória e sociedade: Lembranças dos velhos. 3. ed. São Paulo, Cia das Letras, 1994.

BRANDÃO, C. . O que é educação. São Paulo: Brasiliense, 2007. Col. Primeiros Passos.

BENJAMIN, W. Magia e técnica, arte e política: ensaios sobre literatura e história da cultura. Trad.: Sérgio Paulo Rouanet; Prefácio Jeanne Marie Gagnebin. 7. ed. São Paulo: Brasiliense, 1994. Obras escolhidas; v. 1.

CHAUÍ, M. Cidadania e cultura. São Paulo, Editora Fundação Perseu Abramo, 2006.

DIEGUES, A.C.S. O Vale do Ribeira e Litoral de São Paulo: Meio-ambiente, história e população. Texto preparado para o CENPEC. Março, 2007.

CARNEIRO, C.P. Entrevista realizada em outro de 2014. Barra do Ribeira/Iguape.

FORTES, R. Iguape... Nossa História. Iguape-SP: Gráfica Soset, 2000. vol. 1.

FREIRE, P. Pedagogia do Oprimido, 17. ed. Rio de Janeiro, Paz e Terra, 1987.

Extensão ou comunicação? 6. ed. Trad.: Rosisca Darcy de Oliveira. Rio de Janeiro: Paz e Terra, 1982.

Uma educação para a liberdade. Porto, Portugal: Textos Marginais, 1974.

GOHN, M. G. Educação não-formal e cultura política: Impactos sobre o associativismo no terceiro setor. 3. ed. São Paulo: Cortez, 2005.

GRAMANI, D.; CORRÊA, J.; PIMENTEL, A. (Orgs.) Museu vivo do fandango. Rio de Janeiro: Associação Cultural Caburé, 2006.

HALL, S. A identidade cultural na pós-modernidade. 11. ed. Trad.: Tomaz Tadeu da Silva; Guacira Lopes Louro. Rio de Janeiro: DP\&A Editora, 2006.

PELBART, P.P. Poder sobre a vida, potência da vida. Revista Lugar Comum, n. 17, p.33-43, 2010.

PIMENTEL, A. A confecção de instrumento musicais do fandango caiçara. IPHAN, CNFCP, Rio de Janeiro, 2010.

ROLNIK, S. Cartografia Sentimental: Transformações contemporâneas do desejo. São Paulo: Editora Estação Liberdade, 1989.

Pensamento, corpo e devir. Uma perspectiva ético, estético, política no trabalho acadêmico. Cadernos de Subjetividade, PUC/SP, v. 1 n. 2, p. 241-251, set./fev. 1993.

SANTOS, B.S. Renovar a teoria crítica e reinventar a emancipação social. São Paulo: Boitempo, 2007.

2004.

. (Org.). Conhecimento prudente para uma vida decente: um discurso sobre as ciências revisitado. São Paulo: Cortez,

A crítica da razão indolente: contra o desperdício da experiência. 2. ed. São Paulo: Cortez, 2000.

Novos mapas culturais, novas perspectivas educacionais. Porto Alegre: Sulina, 1996. p. 15-33.

SILVA, N. Entrevista realizada em setembro de 2014, Guaráu/SP.

STREK, D. Pedagogia no encontro de tempos: Ensaios inspirados em Paulo Freire. Petrópolis, RJ: Vozes, 2001.

VALLA, V. V. Sobre participação popular: uma questão de perspectiva. Disp.: <http://www.scielosp.org/pdf/csp/ v14s2/1322.pdf>. Acesso em 04/12/2014.

VOZ CAIÇARA. Um jornal a serviço da comunidade. Iguape, 2010.

Revista Teias v. 18, n. 50, 2017 (Jul./Set.): Conversas sobre formação de professores, práticas e currículos 


\section{RESUMO}

Neste artigo compartilhamos uma pesquisa que realizamos na Associação dos Jovens da Jureia, Iguape, São Paulo. Nasceu da inquietação e análise em torno do modo como a lógica do capital globalizado atua sobre as comunidades tradicionais e as experiências locais, produzindo o sentimento de impotência, inferioridade, insignificância. Tivemos como objetivos: cartografar uma experiência de Oficinas de Fandango na comunidade Caiçara; compartilhar o potencial contra-hegemônico presente nessa experiência e no modo de vida dessa comunidade tradicional. Pudemos identificar como a vida em comunidade, a prática do mutirão, a cultura tradicional caiçara, o encontro entre mestres do Fandango e jovens da Jureia, apresentam-se como uma experiência de Educação Popular e território de reinvenção da vida.

Palavras-chave: Oficina de fandango caiçara, Educação Popular, saber da experiência.

\section{FANDANGO WORKSHOP AT CAIÇARA'S COMMUNITY IN JUREIA/IGUAPE/SP AS POPULAR EDUCATION ABSTRACT}

In this article we share a research we have done about found at the cascara's fandango workshop, produced by Jureia's Youth Association in Iguape/SP. It has been born from the concern and review about how the global capital logic interfere in the traditional communities and the local experiences, producing the feelings of impotence, inferiority and insignificance. We had as aims: mapping an experience of Fandango Workshop in the caiçara's community; collect and to share the counter hegemonic potential present in this local experience and this traditional community way of life. Us to identify how the life in communities, the task force practice, the traditional caiçara's culture, the meeting between the masters of Fandango and young people in Jureia presents it selves as an Popular Education experience and as a territory for the reinvention of life.

Keywords: Caiçara's fandango workshop, Popular Education, knowledge from the experience.

Submetido em Nov./2016

Aceito em Jul./ 2017 